University of Nebraska - Lincoln

DigitalCommons@University of Nebraska - Lincoln

Thermal Characteristics of Wild and Captive Micronesian

Kingfisher Nesting Habitats

\author{
Dylan C. Kesler \\ Oregon State University, Dylan_Kesler@usgs.gov \\ Susan M. Haig \\ U.S. Geological Survey, Susan_Haig@usgs.gov
}

Follow this and additional works at: https://digitalcommons.unl.edu/usgsstaffpub

Kesler, Dylan C. and Haig, Susan M., "Thermal Characteristics of Wild and Captive Micronesian Kingfisher Nesting Habitats" (2004). USGS Staff -- Published Research. 697.

https://digitalcommons.unl.edu/usgsstaffpub/697

This Article is brought to you for free and open access by the US Geological Survey at DigitalCommons@University of Nebraska - Lincoln. It has been accepted for inclusion in USGS Staff -- Published Research by an authorized administrator of DigitalCommons@University of Nebraska - Lincoln. 


\title{
Thermal Characteristics of Wild and Captive Micronesian Kingfisher Nesting Habitats
}

\author{
Dylan C. Kesler, ${ }^{1,2 *}$ and Susan M. Haig ${ }^{1}$ \\ ${ }^{1}$ United States Geological Survey, Forest and Rangeland Ecosystem Science Center, \\ Corvallis, Oregon \\ ${ }^{2}$ Department of Fisheries and Wildlife, Oregon State University, Corvallis, Oregon
}

To provide information for managing the captive population of endangered Guam Micronesian kingfishers (Halcyon cinnamomina cinnamomina), four biologically relevant thermal metrics were compared among captive facilities on the United States mainland and habitats used by wild Micronesian kingfishers on the island of Pohnpei (H. c. reichenbachii), Federated States of Micronesia. Additionally, aviaries where kingfishers laid eggs were compared to those in which birds did not attempt to breed. Compared to aviaries, habitats used by wild Pohnpei kingfishers had $3.2^{\circ} \mathrm{C}$ higher daily maximum and minimum temperatures and the proportion of time when temperatures were in the birds' thermoneutral zone was $45 \%$ greater. No differences were found in the magnitude of temperature fluctuation in captive and wild environments. In captive environments in which birds bred, daily maximum temperatures were $2.1^{\circ} \mathrm{C}$ higher and temperatures were within the thermoneutral zone $25 \%$ more often than in the aviaries where the kingfishers did not breed. No differences were found in the magnitude of temperature fluctuation or the daily minimum temperature. Results suggest that the thermal environment has the potential to influence reproduction, and that consideration should be given to increasing temperatures in captive breeding facilities to improve propagation of the endangered Micronesian kingfisher. Zoo Biol 23:301-308, 2004. Published 2004 Wiley-Liss, Inc. ${ }^{\dagger}$

Key words: Micronesian kingfisher; Halcyon cinnamomina; Pohnpei; captive breeding program; temperature; thermoneutral zone

*Correspondence to: Dylan Kesler, USGS FRESC, 3200 SW Jefferson Way, Corvallis, OR 97331.

E-mail: Dylan_Kesler@usgs.gov

Received for publication May 15, 2003; Accepted October 10, 2003.

DOI 10.1002/zoo.20010

Published online in Wiley InterScience (www.interscience.wiley.com).

Published 2004 Wiley-Liss, Inc. ${ }^{\top}$ This article is a US government work and, as such, is in the public domain in the United States of America. 


\section{INTRODUCTION}

Captive breeding programs for critically endangered species are responsible for providing conditions that encourage animals to reproduce. Some species readily breed in captivity (e.g., Rallus owstoni, Branta sandvicensis [Black and Banko, 1994; Terry, 1996]), while other captive breeding programs have met with only limited success [Snyder et al., 1996] and require the development of specialized breeding protocols (e.g., Leontopithecus rosalia [Kleiman et al., 1991]). Multiple factors can influence the success of a captive breeding program but the captive environment is key when ex situ breeding facilities are used [Millam et al., 1988].

To counter the possible negative effects of captive environments, some have suggested that animals be provided with environments similar to those encountered in their native habitats [Hutchins et al., 1984]. Birds in their native habitats select nest sites with suitable microclimates, presumably to reduce metabolic costs associated with incubation [Gloutney et al., 1996; Thomson et al., 1998; Williams, 1996] and to avoid developmental problems with eggs and chicks [Quinney et al., 1986]. Microclimate factors, including temperature, sunlight exposure, prevailing winds, and moisture can influence nest site selection in the wild [Walsburg, 1985; van Riper et al., 1993] and may influence survival and reproductive success in captive situations. However, natural conditions are often difficult to replicate in captivity due to a lack of information about microclimate conditions used by animals in their native habitats.

Guam Micronesian kingfishers are extinct in the wild and only exist as a captive population [Haig and Ballou, 1995; Haig et al., 1995]. Attempts to breed the birds in captivity have met with limited success [Bahner et al., 1998], as the current population of only 59 individuals illustrates (B. Bahner, personal communication, 7 May 2003). Prior to their extinction in the wild almost 20 years ago, kingfishers on Guam were observed excavating nest cavities from soft-wooded trees and the nests of arboreal termites, or termitaria [Marshall, 1989]. In a study of a closely-related kingfisher on the island of Pohnpei, termitaria used for nesting were found to provide a less stressful thermal environment than other potential nest sites in the forest [Kesler, 2002]. Additionally, kingfishers may be especially susceptible to cold stress because they are not continuously brooded and they hatch as altricial chicks. As Coraciiformes, kingfisher chicks lack the downy stage of development present in other orders; the extended posthatching period when chicks are bare-skinned may further thermally compromise developing nestlings [Fry and Fry, 1992]. Thus, characteristics of wild kingfisher nest sites and the natural history of kingfisher chicks suggest that the birds may be predisposed to thermal stresses. For these reasons, consideration should be given to the thermal conditions of captive breeding facilities housing the Guam kingfisher population.

We initiated this investigation to determine if the thermal characteristics of aviaries used in the captive breeding program are likely to influence reproductive success of the Guam Micronesian kingfishers. Temperatures were recorded in captive breeding facilities and habitats selected by wild Micronesian kingfishers for nesting, and were used to test two predictions. First, we predicted that the thermal properties of wild habitats used by the birds would be metabolically less stressful than the temperature regime in captive breeding facilities. We also predicted that there would 
be a difference in the thermal properties of aviaries where birds laid eggs and those where kingfishers did not breed.

\section{METHODS}

\section{Natural Environment}

Temperatures were recorded at the nest sites of wild Micronesian kingfishers on the island of Pohnpei, Federated States of Micronesia (158.22 $2^{\circ}$ east, $6.88^{\circ}$ north). Pohnpei is a relatively circular island with an approximate diameter of $20 \mathrm{~km}$, circumscribing the highest peak in the Micronesian chain (nearly $800 \mathrm{~m}$ ). Extensive lowland coastal plateau and mangrove swamps surround the inner mountain range, which is characterized by dense tropical rainforests. We selected two study areas 6 $\mathrm{km}$ apart in the Nett $\left(158.21^{\circ}\right.$ east, $6.95^{\circ}$ north $)$ and Sokehs municipalities $\left(158.16^{\circ}\right.$ east, $6.91^{\circ}$ north). The areas were approximately $75 \mathrm{~m}$ in elevation and include secondary-growth lowland rainforest and open pasture.

Within the study areas, Micronesian kingfishers $(n=26)$ were captured, marked with radio telemetry transmitters (Holohil Systems Ltd., Ottawa, Canada), and followed to identify nest sites. We placed StowAway temperature loggers (Onset Computer Corp. Pocasset, MA) approximately $30 \mathrm{~cm}$ below nest cavity entrances at 18 nest termitaria. Temperatures fluctuate throughout the day in Pohnpei, however daily means are extremely stable within and among years (daily mean temp $27.2 \pm$ $0.99^{\circ} \mathrm{C}$ standard deviation [NOAA, 2001]) and suggest that even short-duration monitoring is likely representative of overall thermal patterns. Thus, loggers were set to record ambient temperatures at 6-min intervals during each of three 3-day assessment periods starting at $1900 \mathrm{hr}$ on 6, 10, and 14 September 2001. Pohnpei kingfishers typically nest between June and October (D. Kessler, unpublished observations).

\section{Captive Environment}

To evaluate the thermal characteristics in captive facilities, temperatures were recorded in 15 aviaries containing Guam Micronesian kingfisher pairs from 6 February to 26 October, 2002, the approximate breeding period for the captive population. Sample aviaries were located in nine of 11 institutions attempting to breed the kingfishers, including the Brookfield Zoo, Disney's Animal Kingdom, Houston Zoo, National Zoo, Philadelphia Zoo, St. Louis Zoo, San Diego Wild Animal Park, San Diego Zoo, and the Smithsonian Conservation and Research Center. The same StowAway loggers used in Pohnpei were placed in 15 of 17 aviaries housing the kingfishers. Like those placed in Pohnpei, loggers were mounted approximately $30 \mathrm{~cm}$ below nest cavity entrances. Loggers recorded temperatures at 48-min intervals. Zoo staff at each of the institutions recorded nest initiation dates.

In the wild and in captivity, kingfishers sometimes construct multiple cavities prior to selecting one for nesting. Therefore, only termitaria observed with nest cavities containing eggs were considered to be nests of wild birds. Similarly, captive birds were considered to attempt to breed if at least one egg was laid in a nest cavity during the period when loggers were in the aviaries.

To ensure compliance with legal and ethical standards, work was conducted in accordance with Dawkins and Gosling [1991], and permits were obtained from the 
Chicago Zoological Society, Federated States of Micronesia Office of Historic Preservation, United States Fish and Wildlife Office, and Oregon State University Laboratory Animal Resource Center (Permit \#2703).

\section{Thermoneutral Zone}

Environmental temperatures were compared to the thermoneutral zone (TNZ) of adult Micronesian kingfishers. The TNZ includes temperature ranges not requiring metabolic energy for thermoregulation [Calder and King, 1974; Robbins, 1993]. The upper limit of the TNZ, or the upper critical temperature $\left(T_{u c}\right)$, has a mean of $38 \pm 3^{\circ} \mathrm{C}$ for most avian species [Aschoff, 1981]. Using a formula for inactive nonpasserine birds from Robbins [1993], we estimated the lower limit of the zone, or the lower critical temperature $\left(T_{l c}\right)$, for adult Micronesian kingfishers to be $23.8^{\circ} \mathrm{C}$ :

$T_{l c}=T_{b}-38.3 X^{0.31}$,

where $T_{b}$ is body temperature (estimated as $39.6^{\circ} \mathrm{C}$ ) [King and Farner, 1961], and $X$ is mean body weight (58 g; D. Kessler, unpublished data).

\section{Statistical Analysis}

Four biologically relevant thermal metrics were used to test for differences in temperature regimes in both wild and captive environments. To assess thermal extremes, daily high and low temperatures ( $T_{\max }$ and $T_{\min }$, respectively) were compared; percent coefficients of variation (arcsine square root transformed, $T_{f l u x}$ ) were used to evaluate temperature stability. Historic temperature records from Pohnpei suggest that ambient air temperature is unlikely to go above the kingfisher TNZ, but quite likely to fall below it [NOAA, 2001]. Thus the proportion of observations below $T_{l c}\left(\%\right.$ below $\left.T_{l c}\right)$ was also assessed.

All four metrics were compared among habitats used by wild Micronesian kingfishers on Pohnpei and those in captive facilities. Similarly, aviaries where captive Guam kingfishers laid eggs were compared with those where birds did not attempt to breed. Repeated measures analysis of variance (SAS Analyst, SAS System for Windows 1999; SAS Institute, Cary, NC) was used for $T_{\max }$ and $T_{\min }$ comparisons, and two sample $t$-tests for unequal variance (SAS Analyst) were used for $T_{f l u x}$ and $T_{l c}$. Repeated measures models were fitted with compound symmetry, unstructured, and first order autoregressive (FOA) covariance structures, and results are reported for the model with the lowest Akaike Information Criteria value (AIC) [Burnham and Anderson, 1998]. All variables were treated separately. Means and $95 \%$ confidence intervals (CI) are reported for parameter estimates. Degrees of freedom and sample sizes are reported with $F$ and $t$ statistics for statistical tests and differences are considered statistically significant at $\alpha<0.05$.

\section{RESULTS}

Temperatures in both wild habitats and captive facilities followed similar daily patterns (Fig. 1). Beginning shortly after sunrise (approximately $0700 \mathrm{hr}$ ), temperatures climbed to a mid-day peak around $1000 \mathrm{hr}$. Daily high temperatures at all locations remained below the $T_{u c}$ (approximately $38 \pm 3^{\circ} \mathrm{C}$ ). Afternoon temperatures fluctuated and began to fall at approximately $1500 \mathrm{hr}$. Nocturnal 


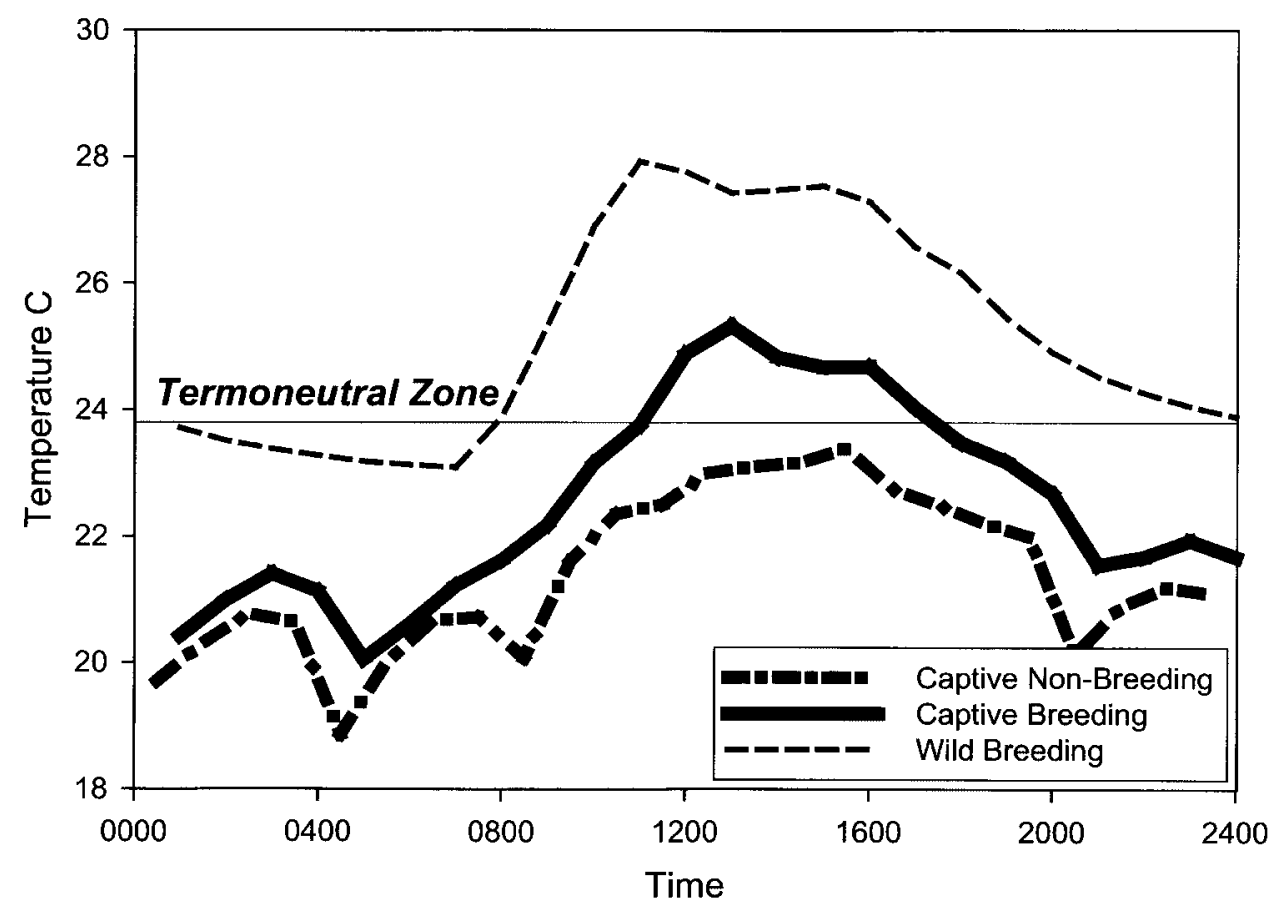

Fig. 1. Mean temperatures throughout the diurnal cycle, for wild Micronesian kingfishers on Pohnpei during the 2001 breeding season and for Guam kingfishers in the captive breeding program during the 2002 breeding season.

temperatures fell to a low temperature trough that lasted from approximately 0000 to $0730 \mathrm{hr}$.

Three of four thermal metrics differed between habitats used by Micronesian kingfishers in Pohnpei and those available to birds in the captive breeding program. Habitats in Pohnpei had a mean $T_{\max } 3.2^{\circ} \mathrm{C}$ higher than captive facilities (Table 1; $F_{1,459}=15.6 ; \quad P<0.0001 ; 1.6$ to $\left.4.8 \mathrm{CI} ; F O A\right)$ and $T_{\min }$ was $3.2^{\circ} \mathrm{C}$ higher $\left(F_{1,166}=8.82 ; P=0.0034 ; 1.1\right.$ to $\left.5.3 \mathrm{CI} ; F O A\right)$. No difference was identified in the amount of temperature fluctuation in the wild and captive habitats $\left(T_{f l u x} ; t_{14.8}=\right.$ $-1.73 ; P=0.45$ ), but temperatures were below the kingfisher $T_{l c} 45 \%$ more often in captive facilities than in the wild $\left(t_{15.8}=-9.75 ; P<0.0001 ; 36\right.$ to $\left.54 \% \mathrm{CI}\right)$.

Aviaries in which birds attempted to breed had daily high temperatures with a mean $T_{\max } 2.1^{\circ} \mathrm{C}$ higher than those in which birds did not lay eggs $\left(F_{1,160}=25.05\right.$; $P<0.0001 ; 1.25$ to $2.87 \mathrm{CI} ; F O A)$. Temperatures were also above $T_{l \mathrm{c}} 25 \%$ more often in breeding aviaries than in non-breeding aviaries $\left(t_{13}=4.39 ; P=0.004 ; 10\right.$ to $40 \% \mathrm{CI})$. No differences were identified in daily low temperatures $\left(T_{\text {min }} ; F_{1,49}=0.13\right.$; $P=0.72 ;-2.23$ to $1.55 \mathrm{CI}, F O A)$, or in temperature fluctuation among breeding and non-breeding aviaries (back transformed $T_{f l u x} ; t_{13}=-6.491 ; P=0.63$ ).

\section{DISCUSSION}

Ambient temperatures have the potential to cause metabolic stress in both adults and nestlings, and can thereby influence reproductive success in the captive 
TABLE 1. Least squares means $( \pm \mathrm{SE})$ of thermal metrics recorded in captive breeding program aviaries and in nesting habitats of wild Micronesian kingfishers during the 2002 and 2001 breeding seasons, respectively

\begin{tabular}{llll}
\hline & \multicolumn{2}{c}{ Captive breeding aviaries } & \multirow{2}{*}{$\begin{array}{c}\text { Pohnpei } \\
\text { nesting }(\mathrm{n}=18)\end{array}$} \\
\cline { 2 - 3 } Thermal metric & Non-nesting $(\mathrm{n}=4)$ & Nesting $(\mathrm{n}=11)$ & $28.6(0.79)^{\mathrm{e}}$ \\
\hline$T_{\max }^{a}$ & $24.2(0.38)^{\mathrm{d}}$ & $25.9(0.23)^{\mathrm{d}}$ & $22.8(0.98)^{\mathrm{e}}$ \\
$T_{\text {min }}^{a}$ & $19.3(0.86)$ & $19.8(0.52)$ & $11.4 \%(<0.1 \%)^{\mathrm{e}}$ \\
$T_{\text {flux }}^{\text {e }}$ & $8.7 \%(0.7 \%)$ & $12.5 \%(0.2 \%)$ & $27 \%(1 \%)^{\mathrm{e}}$ \\
$T_{l c}^{c}$ & $89 \%(1 \%)^{\mathrm{d}}$ & $66 \%(5 \%)^{\mathrm{d}}$ &
\end{tabular}

${ }^{\mathrm{a}} T_{\max }$ and $T_{\min }$ values presented in ${ }^{\circ} \mathrm{C}$.

${ }^{\mathrm{b}} T_{f u x}$ coefficient of variation.

${ }^{\mathrm{c}} T_{l c}$ presented in proportion of observations below lower critical temperature.

${ }^{\mathrm{d}}$ Represents significant difference between breeding and non-breeding captive kingfishers.

${ }^{\mathrm{e}}$ Represents significant difference between Pohnpei habitats and aviaries.

population of Guam Micronesian kingfishers. Adult birds can thermoregulate by adjusting posture or plumage when ambient temperatures are within the TNZ, but metabolic energy must be expended to maintain body heat when temperatures fall below the TNZ [King and Farner, 1961]. Because energy invested in thermoregulation is not available for reproduction, the thermal environment can indirectly influence reproductive success [White and Kinney, 1974].

Results from analyses of temperatures in captive breeding aviaries and habitats used by wild kingfishers suggest that the microclimate influences reproduction in Micronesian kingfishers. Aviaries with Micronesian kingfishers that laid eggs were warmer than those with non-breeding pairs, and temperatures at sites used by wild birds in Pohnpei were warmer than any of the captive breeding facilities. Results also demonstrated that temperatures were within the TNZ for Micronesian kingfishers most frequently in Pohnpei habitats, and least frequently in aviaries in which captive birds chose not to breed.

Metabolic stress associated with weather and environmental temperatures has previously been shown to elevate corticosterone levels in birds [Jeronen et al., 1976; Wingfield, 1985; Rogers et al., 1993; Romero et al., 2000]. An investigation of corticosterone in the captive Guam kingfishers indicated elevated levels of this hormone [Fowler and McGill, 2001]. Although several factors could be responsible for the elevated stress hormones in the captive population, environmental temperatures that are cooler than optimal are a potential contributing factor.

This investigation assessed the relationship between ambient temperature and the probability that captive Guam kingfishers lay eggs. Laying is only the first step in reproduction, however, and ambient temperatures may continue to influence survival during later life-history stages. Results showing temperatures frequently below the kingfisher TNZ suggest that the birds may be further stressed during incubation and brood rearing, when eggs are susceptible to developmental damage from thermal extremes [Quinney et al., 1986] and adults expend metabolic energy keeping eggs warm (i.e., heat increment of incubation) [Robbins, 1993]. Further, nestling kingfishers are especially vulnerable to heat loss due to their greater surfaceto-volume ratios and reduced plumage insulation [Fry and Fry, 1992], and because they are not continuously brooded (D. Kesler, personal observation). 
Multiple factors have been hypothesized to influence population viability in the captive kingfishers, including pair compatibility, nest site availability, disturbance and diseases, and differential survivorship of juveniles [Bahner et al., 1998; Baltz, 1998]. Because there are many challenges to breeding captive kingfishers, thermal stresses are unlikely to be solely responsible for the population's stagnation over the last two decades. Nonetheless, these results suggest that the thermal environment may be an important component to a successful captive breeding program, and that managers should consider increasing temperatures in aviaries and monitoring in-situ captive breeding programs on Guam.

\section{CONCLUSIONS}

1. Ambient thermal environment is a factor that potentially influences whether captive Guam kingfishers elect to breed.

2. Aviaries used for breeding Guam kingfishers in captivity are cooler than nesting habitats selected by wild Pohnpei Micronesian kingfishers, and therefore they may stress birds metabolically.

3. Captive Guam kingfishers seem more likely to breed in aviaries with ambient temperatures that are metabolically less stressful.

4. To provide conditions similar to those used by nesting Micronesian kingfishers in the wild, captive facilities should increase temperatures, to a daily range of 22.8 to $28.7^{\circ} \mathrm{C}$.

\section{ACKNOWLEDGMENTS}

We thank all those who have provided financial and/or technical support to the project, including the U.S. Geological Survey Forest and Rangeland Ecosystem Science Center, U.S. Fish and Wildlife Service, National Fish and Wildlife Foundation, Conservation Endowment Fund of the American Zoo and Aquarium Association, Disney's Animal Kingdom, National Geographic Society, St. Louis Zoo, Brookfield Zoo, Friends of the National Zoo, the Micronesian Kingfisher Species Survival Plan, Riverbanks Zoo, and the Milwaukee County Zoo. Additionally, we appreciate the efforts of the institutions that placed loggers in aviaries and of P. Sanzenbacher and the landowners in Pohnpei who facilitated data collection at wild kingfisher nests.

\section{REFERENCES}

Aschoff J. 1981. Thermal conductance in mammals and birds: its dependence on body size and circadian phase. Comp Biochem Physiol A 69A:611-9.

Bahner B, Baltz A, Diebold E. 1998. Micronesian kingfisher species survival plan husbandry manual. Philadelphia: Zoological Society of Philadelphia. 54 p.

Baltz AP. 1998. The assessment of reproductive potential in Micronesian kingfisher pairs. Zoo Biol 17:425-32.

Black JM, Banko PC. 1994. Is the Hawaiian goose (Branta sandvicensis) saved from extinction? In: Olney PJS, Mace GM, Feistner ATC, editors.
Creative conservation: interactive management of wild and captive animals. London: Chapman and Hall. p $394-410$.

Burnham KP, Anderson DR. 1998. Model selection and inference: a practical informationtheoretic approach. New York: Springer. 353 p.

Calder WA, King JR. 1974. Thermal and caloric relations of birds. In: Farner DS, King JR, editors. Avian biology. Vol. 4. New York: Academic Press. p 259-413.

Dawkins MS, Gosling M. 1991. Ethics in research on animal behavior. London: Academic Press. 64 p.

Fowler GS, McGill P. 2001. Reproductive and stress endocrinology of Micronesian kingfishers. 
Paper presented at the 119th Stated Meeting of the American Ornithologists' Union, August 2001, Seattle.

Fry CH, Fry K. 1992. Kingfishers, bee-eaters, and rollers. Princeton: Princeton University Press. $324 \mathrm{p}$.

Gloutney ML, West N, Clark RG. 1996. Metabolic costs of incubation and clutch size determination in Red Junglefowl. Comp Biochem Physiol A 114A:265-70.

Haig SM, Ballou JD. 1995. Genetic diversity in two avian species formerly endemic to Guam. Auk 112:445-55.

Haig SM, Ballou JD, Casna NJ. 1995. Genetic identification of kin in Micronesian kingfishers. J Hered 86:423-31.

Hutchins M, Hancocks D, Crockett C. 1984. Naturalistic solutions to the behavioral problems of captive animals. Zool Gart 54:28-42.

Jeronen, E, Isometsa P, Hissa R, Pyornila A. 1976. Effect of acute temperature stress on the plasma catecholamine, corticosterone and metabolite levels in the pigeon. Comp Biochem Physiol C 55:17-22.

Kesler DC. 2002. Nest site selection in cooperatively breeding Pohnpei Micronesian Kingfishers (Halcyon cinnamomina reichenbachii): Does nestsite abundance limit reproductive opportunities? [Thesis]. Corvallis, OR: Oregon State University. $86 \mathrm{p}$.

King JR, Farner DS. 1961. Energy metabolism, thermoregulation and body temperature. In: Marshall AJ, editor. Biology and comparative physiology of birds, Vol II. New York: Academic Press. p 215-88.

Kleiman DG, Beck BB, Dietz JD, Dietz LA. 1991. Costs of reintroduction and criteria for success: accounting and accountability in the golden lion tamarin conservation program. In: Gipps JHW, editor. Beyond captive breeding: re-introducing endangered mammals to the wild. Proceedings of Symposium, Zoological Society of London, November 24-25, 1989. Oxford, UK: Clarendon Press; Oxford University Press. p 125-42.

Marshall SD. 1989. Nest sites of the Micronesian kingfisher on Guam. Wilson Bull 101:472-7.
Millam JR, Roudybush E, Grau CR. 1988. Influence of environmental manipulation and nest-box availability on reproductive success of captive cockatiels (Nymphicus hollandicus). Zoo Biol 7:24-34.

NOAA. 2001. National Virtual Data System. Washington, DC: NOAA. http://nndc.noaa.gov.

Quinney TE, Hussel DJ, Ankney CD. 1986. Sources of variation in growth of tree swallows. Auk 103:389-400.

Robbins CT. 1993. Wildlife feeding and nutrition. San Diego: Academic Press. 352 p.

Rogers CM, Ramenofsky M, Ketterson ED, Nolan V Jr, Wingfield JC. 1993. Plasma corticosterone, adrenal mass, winter weather and season in nonbreeding populations of dark-eyed juncos (Junco hyemalis hyemalis). Auk 110:279-85.

Romero LM, Reed JM, Wingfield JC. 2000. Effects of weather on corticosterone responses in wild free-living passerine birds. Gen Comp Endocrinol 118:113-22.

Snyder NFR, Derrickson SR, Beissinger SR. 1996. Limitations of captive breeding in endangered species recovery. Conserv Biol 10:338-48.

Terry CJ. 1996. History and current status of nene in Hawaii. Proceedings of the Western Association of Fish and Wildlife Agencies 76:247-9.

Thomson DL, Monaghan P, Furness RW. 1998. The demands of incubation and avian clutch size. Biol Rev Camb Philos Soc 73:293-304.

van Riper III C, Kern MD, Sogge MK. 1993. Changing nest placement of Hawaiian common amakihi during the breeding cycle. Wilson Bull 105:436-447.

Walsburg GE. 1985. Physiological consequences of microhabitat selection. In: Cody ML, editor. Habitat selection in birds. Orlando, FL: Academic Press. p 389-410.

White FN, Kinney JL. 1974. Avian incubation. Science 186:107-115.

Williams JB. 1996. Energetics of avian incubation. In: Carey $\mathrm{C}$, editor. Avian energetics and nutritional ecology. London: Chapman and Hall, p 375-415.

Wingfield JC. 1985. Influences of weather on reproductive function in female song sparrows, Melospiza melodia. J Zool 205:545-58. 